\title{
Increased leucocyte adhesiveness/aggregation is a most useful indicator of disease activity in patients with inflammatory bowel disease
}

N Arber, S Berliner, A Hallak, Y Bujanover, I Dotan, E Liberman, M Santo, M Moshkowitz, J Ratan, G Dotan, F M Konikoff, M Aronson, T Gilat

\begin{abstract}
The aim of the study was to determine the comparative usefulness of inflammatory markers, in evaluating disease activity in patients with inflammatory bowel disease. Disease activity was assessed by the Mayo Clinic score for ulcerative colitis, and Harvey-Bradshaw score for Crohn's disease. Five hundred normal blood donors who had no underlying inflammatory condition served as controls. The erythrocyte sedimentation rate, platelet and white blood cell count, $C$ reactive protein, and the leucocyte adhesiveness/ aggregation test (LAAT) were determined in each patient. One hundred and twenty four patients with inflammatory bowel disease were tested while in remission and 128 in relapse. Their mean (SD) per cent of aggregated white blood cells in the peripheral blood was 8 (5) and 17 (10) respectively compared with controls 6 (4) $(p<0 \cdot 0001)$. Moreover, the LAAT could effectively discriminate between various grades of disease activity, the values in patients with active disease being $13(6) \%$ in mild, $17(10) \%$ in moderate, and 26 $(10) \%$ in severe disease $(p<0.0001)$. Other acute phase reactants including the erythrocyte sedimentation rate, the white blood cell count, the platelet count, neutrophil count, as well as, the $C$ reactive protein concentration did not differentiate as well between the various groups. Using logistic regression analysis to differentiate between inflammatory bowel disease patients in remission or relapse, the LAAT was the single best indicator. The addition of any other test did not contribute to the discrimination. Among the different laboratory variables tested only the LAAT significantly discriminated between the five different subgroups of controls, remission and mild, moderate or severe disease activity.

(Gut 1995; 37: 77-80)
\end{abstract}

Keywords: disease activity, inflammatory bowel disease, leucocyte adhesiveness/aggregation test.

Knowledge of the severity of inflammation in inflammatory bowel disease (IBD) is important for evaluation, treatment, and prediction of prognosis. To quantify disease severity several clinical scores ${ }^{1-8}$ and biochemical indices ${ }^{9-18}$ for both Crohn's disease (CD) and ulcerative colitis (UC) have been developed; along with the physician's and patient's assessment. These scores, however, were found to be unsatisfactory; partly because of their complexity and partly because of their heavy dependence on subjective symptoms that may be changed by mechanical factors (for example, strictures, resection, etc) rather than by disease activity. The various laboratory indices were also found to be imperfect.

While the extremes in the clinical condition (that is, remission or severe disease) are easily recognised in both $\mathrm{UC}$ and $\mathrm{CD}$, minor changes of disease severity are more difficult to detect or quantify. The large number of proposed scores and indices suggest that none is ideal. In this study we have evaluated prospectively, in a large cohort of IBD patients and controls, the usefulness of several common biochemical markers in estimating disease activity.

\section{Methods}

\section{Patients}

Two hundred and ninety nine blood samples were examined in 160 patients with IBD (84 men and 76 women). Ninety eight patients had $\mathrm{CD}$ and 62 had UC. The mean (SD) age was $33.2(17 \cdot 2)$ and $38.5(18 \cdot 2)$ respectively (range 8-76). Disease activity was assessed by the Mayo Clinic score for UC, ${ }^{5}$ and the HarveyBradshaw score (Softley Clamp modification) for $\mathrm{CD} .^{5}$ Five hundred normal age and sex matched volunteers, who had no underlying inflammatory condition served as controls. All

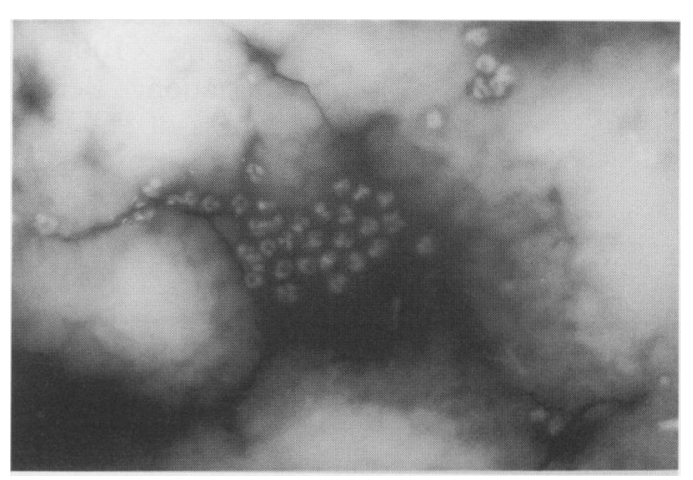

Aggregated leucocytes in the peripheral blood of a patient with severe Crohn's disease. 
TABLE I Laboratory values obtained in patients with IBD and controls

\begin{tabular}{lllcllc}
\hline & ESR & CRP & WBCC & $\% P M N$ & PLT & LAAT(\%) \\
\hline Controls (n=500) & $16(15)$ & $0.5(0.3)$ & $6 \cdot 7(0 \cdot 8)$ & $57(15)$ & $232(88)$ & $6(4)$ \\
Remission (n=124) & $28(20)$ & $1 \cdot 4(1.9)$ & $9 \cdot 1(8 \cdot 0)$ & $72(39)$ & $282(90)$ & $8(5)$ \\
Relapse (n=128) & $44(27)$ & $3.3(3 \cdot 7)$ & $11.0(6 \cdot 7)$ & $71(25)$ & $349(137)$ & $17(10)$ \\
p Value (ANOVA) & 0.0001 & 0.0001 & 0.05 & NS & 0.0001 & 0.0001
\end{tabular}

Data shown as mean $(\mathrm{SD})$. ESR $(\mathrm{mm} / \mathrm{h})=$ erythrocyte sedimentation rate, PLT $\left(10^{3} / \mathrm{mm}^{3}\right)=$ platelet count, WBCC $\left(10^{3} / \mathrm{mm}^{3}\right)=$ white blood cell count, $P M N=\%$ polymorphonuclears, $\mathrm{CRP}(\mathrm{mg} \%)=\mathrm{C}$ reactive protein, LAAT $=(\%)$ leucocyte adhesiveness/aggregation test, ANOVA $=$ one way analysis of variance.

TABLE II Laboratory values obtained in patients with $C D$

\begin{tabular}{lcllllc}
\hline & $E S R$ & CRP & WBCC & $\% P M N$ & PLT & LAAT (\%) \\
\hline Controls (n=500) & $16(15)$ & $0 \cdot 5(0 \cdot 3)$ & $6 \cdot 7(0 \cdot 8)$ & $57(15)$ & $232(88)$ & $6(4)$ \\
Remission (n=73) & $32(21)$ & $1 \cdot 8(2 \cdot 1)$ & $10 \cdot 5(10 \cdot 4)$ & $79(51)$ & $299(83)$ & $8(5)$ \\
Relapse (n=79) & $45(27)$ & $4 \cdot 4(4 \cdot 1)$ & $12 \cdot 2(8 \cdot 0)$ & $73(32)$ & $376(143)$ & $18(10)$ \\
p Value (ANOVA) & 0.001 & 0.0001 & NS & NS & NS & 0.0001 \\
\hline
\end{tabular}

Data shown as mean (SD). Abbreviations as in Table I.

subjects gave their informed consent to the study. Some patients were tested more than once (that is, in remission and relapse), some tests were technically faulty, thus the numbers of tests in Tables I-VI are not identical to the numbers of patients. When a patient was retested it was after an interval of at least four months. Investigators performing the tests (particularly the LAA) were unaware of the clinical situation.

\section{Laboratory methods}

The erythrocyte sedimentation rate was determined according to the method of Westergren, the platelet, white blood cell count, and differential count were performed using a Technicon $\mathrm{H} 1$ autoanalyzer, while the quantitive $C$ reactive protein assay was performed in a turbidometer using a commercial kit. The LAAT was performed using a direct slide test. ${ }^{19}$ In brief, blood is drawn into a syringe that contains sodium citrate (one volume of $3.8 \%$ citrate and three volumes of whole blood). Several large drops of blood are placed on a slide that is held for two to three seconds at an angle of 45 degrees, so that the blood can slip down by gravity, leaving a fine film of blood. The slides are then dried while in a horizontal position in an incubator or at room temperature. The dried slides are placed at $-18^{\circ} \mathrm{C}$ for 10 minutes to start haemolysis. Fixation is done with absolute methanol and staining with haematoxylin. For microscopic examination a drop of immersion oil is placed on the stained slide and covered with a cover glass. The $\times 1000$ ocular is not used for the examination. Because of the comparative thickness of the blood film not all the leucocytes are present on the same level and the focus has to be adjusted often during the

TABLE III Laboratory values obtained in patients with UC

\begin{tabular}{llllllc}
\hline & $E S R$ & CRP & WBCC & $\% P M N$ & PLT & LAAT(\%) \\
\hline Controls (n=500) & $16(15)$ & $0 \cdot 5(0 \cdot 3)$ & $6 \cdot 7(0 \cdot 8)$ & $57(15)$ & $232(88)$ & $6(4)$ \\
Remission (n=51) & $22(17)$ & $1 \cdot 0(1 \cdot 7)$ & $7 \cdot 3(2 \cdot 3)$ & $63(10)$ & $261(95)$ & $8(5)$ \\
Relapse (n=49) & $41(28)$ & $1 \cdot 6(2 \cdot 1)$ & $12 \cdot 2(8 \cdot 0)$ & $68(10)$ & $304(116)$ & $16(10)$ \\
p Value (ANOVA) & 0.0001 & NS & NS & NS & NS & $0 \cdot 0001$ \\
\hline
\end{tabular}

Data shown as mean (SD). Abbreviations as in Table I. examination. The percentage of aggregated leucocytes on the slides is determined by counting 300 white blood cells at random (for example, if 30 of 300 are in aggregates, whether one aggregate of 30 cells or two aggregates of 15, the percentage of aggregated leucocytes is $10 \%$ ). Cells are considered aggregated (Figure) when three or more nuclei are seen less than one cell diameter apart. From each patient, two slides are prepared, and the final result is a simple mean of both. Variation between duplicates does not generally exceed $20 \%$, although from time to time larger differences are seen because of nonhomogenous distribution of the aggregates. ${ }^{20}$ This is also the variation noted when two independent observers examine different slides from the same patient. When the same slide is tested and retested, differences do not exceed $15 \%$. The intra-assay coefficient of variation was calculated from 15 slides, which were simultaneously prepared from the same donor, and the interassay coefficient of variation was calculated when the same normal donor was examined on successive days for 15 consecutive days, the respective values being 0.2 and $0 \cdot 3$. The composition of the aggregates is generally similar to the differential white blood cell count - that is, it is formed mainly of neutrophils in cases of neutrophilia and of lymphocytes in cases of lymphocytosis. Mixed aggregates of polymorphonuclear and mononuclear leucocytes are often seen. ${ }^{21}$ If incubation is used for drying, results of the test can be given within 30 minutes. The statistical analysis was performed by using the SPSS package.

\section{Results}

Table I shows the results of all the laboratory tests in patients with IBD in remission and relapse, as well as the controls. All variables (erythrocyte sedimentation rate, $\mathrm{C}$ reactive protein, white blood cell count, platelet count, LAAT) reached statistical significance after one way analysis of variance except for the per cent of polymorphonuclears; showing that the mean values were different at least between two of the three groups (controls, remission, and relapse). Moreover, the unpaired $t$ test with the Bonferroni correction showed significant differences between all the three inner differential groups (controls, remission, relapse).

In CD patients (Table II) statistically significant differences between each of the three groups (controls, remission, relapse) were found only for LAAT, C reactive protein, and erythrocyte sedimentation rate in that order.

In UC patients (Table III) only the LAAT and erythrocyte sedimentation rate were significantly different between the three groups.

Analysis of the three subgroups of patients with IBD in relapse: with mild, moderate or severe disease (Table IV) showed that only the LAAT and the erythrocyte sedimentation rate showed statistically significant differences. The unpaired $t$ test with the Bonferroni correction showed that the LAAT was significantly differ- 
TABLE IV Laboratory values obtained in patients with active IBD

\begin{tabular}{lllllll}
\hline & $E S R$ & CRP & WBCC & $\% P M N$ & PLT & LAAT(\%) \\
\hline Mild (n=55) & $34(21)$ & $2 \cdot 8(3 \cdot 4)$ & $10 \cdot 1(3 \cdot 7)$ & $69(10)$ & $334(129)$ & $13(6)$ \\
Moderate (n=44) & $48(28)$ & $3 \cdot 5(3 \cdot 4)$ & $11 \cdot 9(9 \cdot 4)$ & $73(38)$ & $350(133)$ & $17(10)$ \\
Severe (n=29) & $55(30)$ & $3 \cdot 9(4 \cdot 7)$ & $11 \cdot 0(4 \cdot 4)$ & $70(11)$ & $373(157)$ & $26(10)$ \\
p Value (ANOVA) & 0.002 & NS & NS & NS & NS & 0.0001 \\
\hline
\end{tabular}

Data shown as mean (SD). Abbreviations as in Table I.

TABLE V Laboratory values obtained in patients with active $C D$

\begin{tabular}{lclllll}
\hline & $E S R$ & CRP & WBCC & $\% P M N$ & PLT & LAAT(\%) \\
\hline Mild (n=32) & $34(21)$ & $4 \cdot 0(3 \cdot 8)$ & $10 \cdot 9(4 \cdot 3)$ & $72(11)$ & $348(136)$ & $14(7)$ \\
Moderate (n=30) & $52(27)$ & $4 \cdot 2(3 \cdot 8)$ & $13 \cdot 4(10 \cdot 9)$ & $76(46)$ & $384(134)$ & $18(10)$ \\
Severe (n=17) & $54(29)$ & $5 \cdot 1(5 \cdot 3)$ & $11 \cdot 8(4 \cdot 7)$ & $68(10)$ & $412(166)$ & $27(10)$ \\
p Value (ANOVA) & $0 \cdot 001$ & NS & NS & NS & NS & $0 \cdot 0001$ \\
\hline
\end{tabular}

Data shown as mean (SD). Abbreviations as in Table I.

ent between all the three groups, while the erythrocyte sedimentation rate was significantly different only between patients with mild and severe disease. In patients with active CD (Table V) only the LAAT $(p<0.0001)$ and the erythrocyte sedimentation rate $(p<0.001)$ showed significant differences. In patients with active UC only the LAAT showed significant differences between the groups (Table VI). Considering all IBD patients and controls there were five subgroups of control, remission, mild, moderate, and severe disease. To detect differences between all these the unpaired $t$ test with the Bonferroni correction was performed. Among all the different variables only the LAAT significantly discriminated between the five different subgroups $(p<0.05)$. Erythrocyte sedimentation rate was the second best indicator. It did not discriminate between patients with mild and moderate or moderate and severe activity. In patients with CD the LAAT and erythrocyte sedimentation rate were both able to differentiate between patients in remission, and patients with mild disease. They were unable, however, to discriminate between mild, moderate, and severe activity. In UC patients all the variables could distinguish between patients in remission and relapse, however, only the LAAT was sensitive enough to discriminate between remission and mild disease.

Using logistic regression analysis to differentiate between IBD patients in remission or relapse, the LAAT was the single best indicator. The addition of any other test did not contribute to the discrimination. The $p$ values obtained for the LAAT, erythrocyte sedimentation rate, $\mathrm{C}$ reactive protein, white blood cell count, $\%$ polymorphonuclears, and platelet count were $0.0001,0.0990,0.1471,0.2774$, $0.5740,0.9672$ respectively. When the LAAT was not considered in the logistic regression analysis the erythrocyte sedimentation

TABLE VI Laboratory values obtained in patients with active UC

\begin{tabular}{lllllll}
\hline & ESR & CRP & WBCC & $\% P M N$ & PLT & LAAT(\%) \\
\hline Mild (n=23) & $35(23)$ & $1 \cdot 1(1 \cdot 6)$ & $9 \cdot 0(2 \cdot 4)$ & $67(9)$ & $314(119)$ & $11(4)$ \\
Moderate (n=14) & $38(30)$ & $2 \cdot 0(1 \cdot 9)$ & $8 \cdot 5(2 \cdot 2)$ & $68(9)$ & $274(95)$ & $16(9)$ \\
Severe (n=12) & $56(32)$ & $2 \cdot 2(3 \cdot 0)$ & $9 \cdot 9(3 \cdot 8)$ & $72(13)$ & $325(137)$ & $24(12)$ \\
p Value (ANOVA) & NS & NS & NS & NS & NS & 0.0003 \\
\hline
\end{tabular}

Data shown as mean (SD). Abbreviations as in Table I. rate became the best indication $(p<0.001)$, however, the addition of the platelet count or the $\mathrm{C}$ reactive protein, or both, significantly improved the differentiation. The same findings were noted when UC and CD patients were analysed separately.

\section{Discussion}

Inflammation confers upon the white blood cells increased adhesive properties. ${ }^{22}$ This adhesiveness has a known biological role regarding leucocyte - endothelial cell interactions. ${ }^{23}$ It has been repeatedly shown in the past that the increased adhesiveness of these cells can be used for diagnostic purposes ${ }^{24-30}$ including patients with IBD. ${ }^{31}$ In this study we have shown, in a comparatively large number of patients and controls that the LAAT is an excellent morphological parameter for determining disease activity and quantifying inflammation. In this regard it is clearly superior to other commonly used acute phase reactants including the erythrocyte sedimentation rate, the white blood cell count, the platelet count, the neutrophil count as well as quantitative $C$ reactive protein measurements. It can be seen that by using the LAAT, that not only can the presence or absence of inflammation in patients with IBD be assessed but also the disease activity; a finding that might have clinical implications for both diagnostic and monitoring purposes.

One of the problems in IBD is determining the intensity of the disease, namely the inflammatory activity. Various clinical ${ }^{1-8}$ and laboratory tests ${ }^{9-18}$ have been used to solve this problem with only partial success. The problem whether a physician intends to measure disease activity or quantify inflammation, has been one of the problems in the use of clinical indices. Singleton, ${ }^{12}$ in his attempts to define some of the terms, had separated the terms illness (subjective and objective manifestations of the disease) from inflammation (the pathological process) and differentiated between disease activity and degree of illness. The ideal biochemical marker of disease activity in IBD should reflect the disease extent and the severity of inflammation. A substantial number of acute phase reactants and other parameters of inflammation are changed in relation to active disease, however, the types of biochemical parameters that should preferentially be used has not been established. ${ }^{32}$ Using the consensus of all variables measured as a gold standard, the platelet count, followed by the erythrocyte sedimentation rate and $C$ reactive protein correlated best with the final consensus in $\mathrm{CD} .{ }^{33}$ Orosomucoid has been shown by others, to correlate best with clinical severity. ${ }^{34}$ Nevertheless we still lack a truly reliable laboratory indicator of the activity of CD. ${ }^{35} \mathrm{In}$ this study the LAAT was the most useful test. It is possible that the leucocytes 'sense' the inflammatory mediators during their sojourn in the mesenteric capillaries of the inflamed intestinal segments and then present their stickiness in the peripheral circulation as shown in the adhesiveness test. It is tempting 
to assume that a correlation exists between the degree of intestinal inflammation and degree of adhesiveness of the cells. This study, which clearly shows a correlation between disease activity and degree of leucocyte adhesiveness, strongly supports this notion. In fact, we have already shown in the past that the LAAT correlates with inflammatory disease activity and that this adhesiveness is correlated to tissue leucostasis. ${ }^{24-30} \mathrm{~A}$ stasis like this could contribute to unfavourable local rheology. The role of this increased LAA could be important in determining the extent of ischaemic heart disease or cerebrovascular event. ${ }^{3637}$ Such leucostasis is probably present in the inflamed intestine.

Our findings might be relevant in view of studies ${ }^{38-41}$ showing that by reducing the adhesiveness of white blood cells it is possible to attenuate the inflammatory response. Steroidal and non-steroidal anti-inflammatory agents can reduce the adhesiveness of the leucocytes, and studies are in progress to use antibodies directed to the adhesive epitopes on the leucocytes. Therefore, we believe that our findings should be considered in a broad biological sense of the disease and not taken solely as another acute phase reactant.

We conclude that the LAAT is superior to other acute phase reactants currently used in daily practice to detect the presence of inflammation as well as for the assessment of its severity. In addition, our findings might have biological relevance to the disease process in patients with IBD and its potential manipulation by anti-adhesive agents.

This study was partially supported by The Shmuel Shalit Foundation, Tel Aviv University. Part of this material is included in the MD thesis of Gad Dotan, Tel-Aviv University.

1 Singleton JW. Laboratory investigations and disease activity in inflammatory bowel disease. In: Allan RN, Keighley MRB, Alexander-Williams J, Hawkins C, eds. Inflammatory bowel disease. Edinburgh: Churchill Livingstone, 1990: 199-206.

2 Singleton JW. Clinical activity assessment in inflammatory bowel disease. Dig Dis Sci 1987; 32: 42-5S.

3 De Dombal FT. Measuring and quantifying the status of patients with inflammatory bowel disease. In: Inflammatory bowel disease. Some international reflection. Oxford: Oxford University Press, 1986: 267-85

4 Truelove SC, Witts LJ. Cortisone in ulcerative colitis. Final report on a therapeutic trial. BMF 1955; 2: 1041-8.

5 Myren J, Bouchier IAD, Watkinson G, Softley A, Clamp SE, de Dombal FT. The OMGE multinational inflammaSE, de Dombal FT. The OMGE multinational inflammatory bowel disease survey 1976-1982: a further report on 2657 cases. Scand 7 Gastroenterol Suppl 1984; 95: 1-27.
Best WR, Becktel JM, Singleton JW, Kern F. Development of a Crohn's disease activity index: National Cooperative Crohn's Disease Study. Gastroenterology 1976; 70: 439-44.

7 Harvey RF, Bradshow JM. A simple index of Crohn's disease activity. Lancet 1980; 1: 514.

8 Van Hees PAM, van Elteren $\mathrm{PH}$, van Lier $\mathrm{HJ}$, van Tongeren JHM. An index of inflammatory activity in patients with Crohn's disease. Gut 1980; 21: 279-86.

9 Sachar DB, Smith H, Chan S, Cohen LB, Lichtiger S, Messer J. Erythrocytic sedimentation rate as a measure of clinical activity in inflammatory bowel disease. $\exists$ Clin Gastroenterol 1986; 8: 647-50.

10 Chambers RE, Stross P, Barry RE, Whicher JT. Serum amyloid A protein compared with C-reactive protein amyloid A protein compared with C-reactive protein, alpha 1 -antichemotrypsin and alpha 1 -acid glycoprotein, Invest 1987; 17: 460-7.

11 Fagan EA, Dyck RF, Maton PN, Hodgson HJF, Chadwick VS, Petrie A, et al. Serum levels of C-reactive protein in Crohn's disease and ulcerative colitis. Eur $\mathcal{f}$ Clin Invest 1982; 12: 351-9.

12 Andre C, Descos L, Vignal J, Gillon J. C-reactive protein as a predictor of relapse in asymptomatic patients with Crohn's disease. Scott Med f 1983; 28: 26-9.
13 Dearing WH, McGuckin WF, Elveback LR. Serum alfa acid glycoprotein in chronic ulcerative colitis. Gastroacid glycoprotein in chronic

14 Helman CA, Novis BH, Bank S, Wormold L, Jacobs P. Serum lysozyme in Crohn's disease and ulcerative colitis $S$ Afr Med F 1977; 52: 1042-4.

15 Jensen KB, Jarnum S, Koudahi G, Kristensen M. Serum orsomucoid in ulcerative colitis: its relation to clinical activity, protein loss, and turnover of albumin and IgG. Scand $\mathcal{f}$ Gastroenterol 1976; 11: 177-83.

16 Fiasse R, Lurhuma AZ, Cambiaso CL, Masson PL, Dive C. Circulating immune complexes and disease activity in Crohn's disease. Gut 1978; 19: 611-7.

17 Talstad I, Gjone E. The disease activity of ulcerative colitis and Crohn's disease. Scand 7 Gastroenterol 1976; 11: 403-8. 18 Cooke WT, Prior P. Determining disease activity in inflammatory bowel disease. F Clin Gastroenterol 1984; 6: 17-25.

19 Berliner S, Fishelson Z, Bruhis S, Kaufman H, Pinkhas J Aronson $M$. The phenomenon of leukergy: induction and detection of leukocyte aggregation in whole human blood. f Lab Clin Med 1987; 109: 575-82.

20 Galante A, Carta S, Domenic B, Pietroiusti A. Proposal of a new method to avoid misinterpretations in the evaluation of the leukergy test. Scand 7 Clin Lab Invest 1992; 52 431-3.

21 Arber N, Berliner S, Pras E, Arber L, Fishelson Z, Ben Bassat $M$, et al. Heterotypic leukocyte aggregation in the peripheral blood of patients with leukemia inflammation or stress. Nouv Rev Fr Hematol 1991; 33: 251-5.

22 Lentek AL, Schreiber AD, MacGregor RR. The induction of augmented granulocyte adherence by inflammation. Mediation by a plasma factor. F Clin Invest 1976; 57 1098-103.

23 Harlan JM. Leukocyte - endothelial interactions. Blood 1985; 65: 513-25.

24 Berliner S, Abramovitz M, Kariv N, Weinberger A, Yaron $\mathrm{M}$, Lavie $\mathrm{G}$, et al. The leukergy test in rheumatological diseases: new implications for an old test. Arthritis Rheum 1985; 28: 899-903.

25 Berliner S, Fried M, Caspi D, Weinberger A, Yaron M, Pinkhas J, et al. Evaluation of disease activity in rheumatic patients by use of the state of leukocyte adhesiveness/ patients by use of the state of leukocyte adhe
aggregation. Ann Rheum Dis 1988; 47: 458-62

26 Berliner S, Caspi D, Neuman Y, Ostfeld I, Hod M, Yaron M, et al. Aggregation of white cells and C-reactive protein. A study on the relation between these two indices of the A study on the relation between these two indices of
acute phase reaction. $\mathcal{F}$ Clin Pathol 1987; 40: 103-6.

27 Fadilah R, Berliner S, Kidron D, Ben-Bassat M, Frumkin $\mathrm{R}$, Jaffe A, et al. The state of leukocyte adhesiveness/aggregation in the peripheral blood of patients with respiratory tract infection. Respiration 1990; 57: 109-13.

28 Molad Y, Berliner S, Arber N, Kidron D, Sternberg E, Ben-Bassat $M$, et al. Increased leukocyte adhesiveness aggregation and tissue leukostasis following surgical trauma. Int Surg 1993; 78: 20-4.

29 Fried M, Ben-Hur N, Berliner S, Medalia O, Aronson M. The state of leukocyte adhesiveness/aggregation (LAA) in the peripheral blood of burned mice: an early and sensitive inflammatory indicator and a marker of pulmonary inflammatory indicator and a ma
leukostasis. Burns 1991; 17: 458-61.

30 Otremski I, Newman RJ, Kahn RJ, Stadler J, Kariv N, Skornik Y, et al. Leukergy - a new diagnostic test for bone infection. F Bone foint Surg 1993; 75: B734-6.

31 Goldman G, Kahn P, Aronson M, Kariv N, Stadler J, Wiznitzer T. Leukergy in inflammatory bowel disease. Dis Colon Rectum 1988; 31: 854-6.

32 Kjeldsen J, De Muckadell OBS. Assessment of disease severity and activity in inflammatory bowel disease. Scand f Gastroenterol 1993; 28: 1-9.

33 Lobo AJ, Sobala GM, Juby LD, Jones SC, Rathbone BJ, Axon ATR. Evaluation of indices of disease activity in Crohn's disease by consensus analysis. European fournal of Gastroenterology and Hepatology 1991; 3: 663-6.

34 Andre C, Descos L, Landais P, Fermanian J. Assessment of appropriate laboratory measurements to supplement the appropriate laboratory measurements to supplement

35 Korelitz BI. An indicator of Crohn's disease activity: a need unfulfilled. $\mathcal{f}$ Clin Gastroenterol 1986; 8: 220-2.

36 Aspey BS, Jessimer C, Pereiera S, Harrison MJG. Do leukocytes have a role in the cerebral no-reflow phenomenon? f Neurol Neurosurg Psychiatry 1989; 52: 526-8.

37 Dinerman JL, Mehta JL. Endothelial, platlet and leukocyte interaction in ischemic heart disease: insight into potential mechanisms and their clinical relevance. $\mathcal{f} \mathrm{Am}$ Coll Cardiol 1990; 16: 207-12.

38 Clark WM, Madden KP, Rothlein R, Zivin JA. Reduction of central nervous system ischemic injury in rabbits using 877-83.

39 Simpson PJ, Todd RF, Fantone JC, Mickelson JK, Griffin JD, Lucchesi BR, et al. Reduction of experimental canine myocardial reperfusion injury by a monoclonal antibody (anti-Mol, anti-CD 11b) that inhibits leukocyte adhesion. $\mathcal{F}$ Clin Invest $1988 ; 81: 624-9$.

40 Simpson PJ, Todd TR, Mickelson JK, Fantone JC, Gallaghe $\mathrm{KP}$, Lee KA, et al. Sustained limitation of myocardial reperfusion injury by a monocolonal antibody that alters leukocyte function. Circulation 1990; 81: 226-37.

41 Carlos TM, Harlan KM. Membrane proteins involved in phagocyte adherence to endothelium. Immunol Rev 1990 114: 5-28. 